\title{
NARRATIVAS AUTOBIOGRÁFICAS DE LUTAS PELA EDUCAÇÃO: PEDAGOGIAS EMERGENTES DE UMA OCUPAÇÃO
}

RAFAEL ARENHALDT

https://orcid.org/0000-0002-0424-1990

Universidade Federal do Rio Grande do Sul

aLEXSANDRO DOS SANTOS MACHADO

https://orcid.org/0000-0001-9568-094X

Universidade Federal Rural de Pernambuco

- IRENE REIS DOS SANTOS

https://orcid.org/0000-0001-5235-6592

Universidad de la Empresa

ERIKA CRISTINA LIMA DA SILVA SANTIAGO

https://orcid.org/0000-0001-7041-5162

Centro Universitário FACOL

RESUMO Este artigo tem como cenário o movimento plural e (in)tenso de manifestação e ocupação estudantil em uma universidade federal, em 2016. Nele, intentamos reconhecer e analisar as pedagogias emergentes advindas de escritas autobiográficas de universitários de um movimento de ocupação. Para tanto, operamos com os pressupostos teórico-metodológicos que surgem das noções de duração e memória (Bergson), hermenêutica da experiência, autobiografização e heterobiografização (Delory-Momberger; Passeggi), num movimento situado da pesquisa (auto)biográfica como dispositivo formativo em educação. Destacamos a potencialidade de uma escuta sensivel, aberta, a(fe)tiva, ética e aprendente, a partir de uma ambiência de luta, defesa e protagonismo. Por fim, refletimos sobre as pedagogias emergentes das experiências acontecidas, tecidas e entretecidas nas escritas dos estudantes, expressas nas pedagogias da indignação, da outreidade e da cidadania. Outrossim, merece destaque a potência que reinventa o educativo e o formativo, institui novos modos de fazer universidade e de compreender estudante e pessoa, bem como ressignificar o sentido de coletivo, anunciar as experiências de luta 
pela educação e a compreensão de um movimento de ocupação.

Palavras-chave: autobiografias. Narrativas. Ocupações. Pedagogias emergentes.

\section{ABSTRACT AUTOBIOGRAPHICAL NARRATIVES OF STRUGGLES FOR EDUCATION: PEDAGOGIES EMERGING FROM AN OCCUPATION}

The setting of this article is the plural, (in)tense movement of students' demonstrations at and occupation of a Federal University in Brazil in 2016. Here, we try to acknowledge and analyze the pedagogies emerging from autobiographical pieces of writing of college students in an occupation movement. We operated with theoretical-methodological presumptions based on the notions of duration and memory (Bergson), hermeneutics of experience, and autobiographies and heterobiographies (Delory-Momberger; Passeggi), in a movement located in the (auto)biographical study as a formative device in education. We highlight the potential of listening in a sensitive, open, ethical, learning, and a(ffe)ctive manner, in a context of fight, defense, and protagonism. We finally reflect on the pedagogies emerging from those experiences, woven and interwoven in students' writings, and expressed in the Pedagogies of Indignation, Otherness, ad Citizenship. The power that reinvents education and formation, institutes new ways of making university and understands the student and the person must also be highlighted. This power also resignifies the meaning of collective and announces the experiences of understanding an occupation movement and fighting for education. We finally reflect on the pedagogies emerging from those experiences, woven and interwoven in students' writings, and expressed in the Pedagogies of Indignation, Otherness, ad Citizenship. The power that reinvents education and formation, institutes new ways of making university and understands the student and the person must also be highlighted. This power also resignifies the meaning of collective and announces the experiences of understanding an occupation movement and fighting for education.

Keywords: autobiographies. Narratives. Occupations. Emerging pedagogies.

\section{RESUMEN NARRATIVAS AUTOBIOGRÁFICAS DE LAS LUCHAS POR LA EDUCACIÓN: PEDAGOGÍAS QUE EMERGEN DE UNA OCUPACIÓN}

Este artículo tiene como escenario el movimiento plural e (in)tenso 
de manifestación y ocupación estudiantil de una Universidad Federal, en 2016. En él, intentamos reconocer y analizar las pedagogías emergentes que resultan de escritas autobiográficas de universitarios de un movimiento de ocupación. Para ello, operamos con los supuestos teórico-metodológicos que surgen de las nociones de duración y memoria (Bergson), hermenéutica de la experiencia, autobiografia y heterobiografia (Delory-Momberger; Passeggi), en un movimiento ubicado en la investigación (auto)biográfica como dispositivo formativo en educación. Destacamos la potencialidad de la escucha sensible, abierta, a(fe)ctiva, ética y aprendiente, desde un ambiente de lucha, defensa y protagonismo. Por fin, reflexionamos sobre las pedagogías emergentes de las experiencias acontecidas, tejidas y entretejidas en los escritos de los estudiantes, expresadas en las Pedagogías de la Indignación, de la Otredad y de la Ciudadanía. Además, merece destaque el poder que reinventa lo educativo y lo formativo, instituye nuevas formas de hacer universidad y de comprender estudiante y persona, así como resignificar el sentido del colectivo, anunciando las experiencias de lucha por la educación y la comprensión de un movimiento de ocupación.

Palabras clave: autobiografia. Narrativas. Ocupaciones. Pedagogías emergentes.

\section{Primeiras palavras: das}

\section{pedagogias emergentes}

Etenim, Quirites, exiguum nobis vitae curriculum natura circumscripsit, immensum gloriae. (Cícero)

O que foi o movimento CAV r_Existe? Foi um movimento que teve como alicerce os desejos e anseios de uma juventude que não aceitava a situação e o possivel cenário político de perdas de direitos e da ampliação de desigualdades. Um movimento não partidário, buscando os alicerces da democracia e horizontalidade e tendo como ponto principal o sentimento de humanização. Pois foi criada uma grande família em que as relações humanas e sociais do $\mathrm{CAV}^{2}$ passaram a ter uma outra dimensão, já que o

1 "E, de fato, ó romanos, a natureza circunscreveu (circumscripsit) estreitamente o curso de nossa vida (curriculum vitae), glória incomensurável" (tradução nossa). Tal inscrição é encontrada no discurso "Em defesa de Rabirio" (Pro Rabirio Perduellionis Reo, [30], 63 a.C).

2 Centro Acadêmico de Vitória (CAV) da Universidade Federal de Pernambuco (UFPE). outro passou a ter valor, a luta não era pessoal, mas sobretudo pelo outro, pelas futuras gerações, pelas famílias, pela comunidade, pela sociedade brasileira. (M.J.S., 2016, linhas 59-68) ${ }^{3}$

"R_Existir!" Essa foi a palavra de ordem de um movimento estudantil de ocupação de um campus de uma universidade federal na zona da mata pernambucana, no ano de 2016. Tal movimento pacífico não foi o único, naquele turbulento contexto sociopolítico brasileiro, mas foi um dos primeiros em contexto nacional. Em todo país, estudantes da educação básica e do ensino superior ocuparam centenas

3 As narrativas autobiográficas escritas pelos estudantes universitários participantes da ocupação e utilizadas neste trabalho são apresentadas a partir das iniciais dos nomes, mantendo assim o anonimato. Todas narrativas estudadas neste artigo foram devidamente autorizadas pelos seus autores. 
de instituições públicas (CAVALCANTI, 2019) como reação à Proposta de Emenda à Constituição (PEC) no 241/55 (2016) 4 que previa cortes e congelamentos de gastos públicos, incluindo os com a educação. Mesmo com toda mobilização de estudantes, professores e movimentos sociais, a PEC foi aprovada, transformandose na Emenda Constitucional no 95 (2016). ${ }^{5}$ O observador menos atento poderia inferir que tanta mobilização fora, portanto, inócua. Entretanto, àqueles que estudam os processos educacionais que transcendem os currículos e planos de ensino previamente determinados, cabe investigar os caminhos de formação humana promovidos por aquele movimento de (r)existência.

Sendo assim, de nossa parte, neste artigo, analisamos, por meio de uma hermenêutica prática, as pedagogias emergentes a partir das narrativas das experiências vividas -autobiografizações - e das escutas das narrativas dos outros - heterobiografizações - (PASSEGGI; OLIVEIRA; CUNHA, 2018) de estudantes de uma universidade pública, no interior do estado de Pernambuco, em um movimento de ocupação intitulado "CAV r_Existe".

Iniciemos, para tanto, debruçando-nos sobre o nome com o qual os estudantes batizaram o movimento de ocupação do espaço público da universidade. Ao atribuir ao campus universitário - Centro Acadêmico de Vitória (CAV) da Universidade Federal de Pernambuco (UFPE) - a ação de resistir como forma de existir, conjugando-a no tempo presente, os estudantes problematizaram os sentidos da existência da universidade pública e suas funções sociais. Afinal, o que significaria cursar uma universidade pública? Quais seriam seus per-

4 PEC no 241/55. Disponivel em: https://www.camara. leg.br/proposicoesWeb/fichadetramitacao?idProposicao=2088351. Acesso em: 15 maio 2020.

5 Emenda Constitucional no 95. Disponível em: https:// www2.camara.leg.br/legin/fed/emecon/2016/emendaconstitucional-95-15-dezembro-2016-784029-publicacaooriginal-151558-pl.html. Acesso em: 15 maio 2020. cursos de formação? Quais os currículos ${ }^{6}$ que formam os estudantes universitários?

Foi por meio de uma práxis política coletiva que seus participantes tanto refletiram sobre os sentidos dos processos de instrumentalização técnica e acadêmica para o exercício profissional no futuro, como também se autobiografaram e heterobiografaram, ressignificando suas vidas, em (com)vivências frente aos desafios apresentados pelo tempo presente.

Delory-Momberger (2014, p. 33-34), a propósito, nos recorda que os seres humanos se apropriam de suas vidas por meio de histórias. E, para tanto, ao comunicá-las, eles figuram suas existências para representar seu desenvolvimento temporal. Dentre tais representações, a figura do caminho, do percurso, da carreira é uma das mais utilizadas. Porém, ao longo do tempo, a própria representação do caminho foi distinta.

Na epígrafe deste artigo, por exemplo, Cícero ${ }^{7}$ apresenta o curso de uma vida -curriculum vitae - como constructo, a partir de um curso dos astros - curriculum stellarum -, previamente inscrito - circumscripsit. Trata-se de uma noção de curso da vida, dentro de uma cosmologia platoniana, ${ }^{8}$ por meio da qual a alma realiza, num corpo humano, um caminho, uma carreira de acordo com o bem, voltando, posteriormente, ao final da existência sensivel e terrena, para morar no mundo ideal.

Em nosso mundo contemporâneo, todavia, as formas do modelo biográfico sofreram grandes alterações. O curriculum vitae apresentado para quaisquer entrevistas de emprego, por exemplo, é composto por um conjunto de experiências acadêmicas e profissionais que proporcionaram uma formação singular, evi-

6 Em latim, curricula: "caminhos".

7 Marco Túlio Cícero (106-3 a.C.) foi um advogado, político, escritor, orador e filósofo da República Romana. Sua influência na língua latina, história e literatura foi imensa e suas ideias estão presentes no mundo ocidental, até os nossos dias.

8 Cícero traduziu o Timeu, de Platão, para o latim. 
denciando um conjunto de capacidades e habilidades para o exercício de um ofício.

Nesse sentido, a universidade, instituição criada na Idade Média, parece exercer um misto dessas concepções acerca dos caminhos - curricula - e seus cursos de formação dos seres humanos. Por um lado, geralmente apresenta projetos político-pedagógicos de cursos nos quais se evidenciam currículos homogêneos, com perfis de egressos idealizados a serem forma(ta)dos, por meio de pedagogias igualmente homogêneas, em vista de um futuro idealmente esperado. Herdeiras da pedagogia tradicional, no contexto brasileiro, ainda se verifica a existência da concepção do professor como o detentor do conhecimento a ser transmitido ao aluno, que o recebe, passivamente, com seu corpo silenciado em carteiras enfileiradas, em disposições incomunicáveis e pouco ou nada colaborativas. Por outro lado, a universidade pode proporcionar, mesmo que de modo não formal ou planejado, um conjunto de experiências, de percursos pessoais e coletivos que, potencialmente, ofereçam aos acadêmicos a reinvenção de si mesmos e do mundo, por meio de outras narrativas possíveis de si, do outro, da universidade, das comunidades, das sociedades e do futuro.

No escopo deste trabalho, compreendemos as experiências práticas, ideias, pistas, sinais e formas sociais possiveis que emergem e ganham presença nas escritas autobiográficas, produzidas e compartilhadas pelos estudantes entre si, em uma ambiência política de uma ocupação, como pedagogias das emergências, analogia ao que Santos (2007) denomina de "sociologia das emergências".

9 Ao propor uma sociologia insurgente e contra o desperdício da experiência, Santos (2007, p. 32) destaca ecologias criando as possibilidades de que essas experiências ausentes se tornem presentes. Assim, as ecologias nos permitem um duplo movimento: dilatar o presente por meio das experiências significativas e contrair o futuro.
Tentaremos ver quais são os sinais, as pistas, latência, possibilidades que existem no presente e que são sinais do futuro, que são possibilidades emergentes e que são descredibilizadas porque são embriões, porque são coisas não muito visíveis [...] o que não existe mas está emergindo [...]. (SANTOS, 2007, p. 37)

Assim, analisamos, hermeneuticamente, as narrativas autobiográficas de estudantes participantes do movimento CAV r_Existe a fim de compreendermos: (i) quais pedagogias emergem a partir das experiências dos(as) estudantes em luta? (ii) Que pistas e possibilidades, que contornos de outros mundos possiveis, emergem a partir dos relatos de (com)vivências dos jovens na ambiência da ocupação?

A propósito, utilizamos o termo "pedagogias", no plural, no escopo da obra de Paulo Freire que, ao longo de sua trajetória, elaborou diferentes definições de pedagogias. Nesse sentido, Streck (2018) propõe uma atualização do significado do conceito de pedagogia associando-o a práticas educativas concretas, realizadas por educadores e educadoras:

Pedagogia, palavra derivada do grego pais (criança) e ago (conduzir), significa a condução de crianças. $O$ conceito hoje abrange todas as faixas etárias e todos os contextos em que se realizam processos de ensino-aprendizagem. A Pedagogia tornou-se também um campo de estudos, integrando a grade de cursos universitários. [...] se situa no âmbito dessa tensão, em que prática e teoria estão em permanente diálogo. Nesse sentido, pedagogia refere-se a práticas educativas concretas realizadas por educadores e educadoras, profissionais ou não. Vem a ser o próprio ato de conhecer, no qual o educador e a educadora têm um papel testemunhal no sentido de refazer diante dos educandos e com eles, o seu próprio processo de aprender a conhecer. (p. 358-359)

Dessa forma, analisamos, neste trabalho, as pedagogias emergentes (MACHADO; ARENHALDT, 2016), expressas pelos testemunhos de estudantes que, numa ambiência de ocu- 
pação, de luta pela educação, tornaram-se educadores e educadoras de si mesmos, dos seus pares, dos profissionais da educação da universidade e da comunidade extramuros do campus universitário.

Assim sendo, na sequência deste texto, ao caracterizarmos os espaços e tempos de uma ocupação e das lutas em defesa da educação, operamos com as noções de duração, memória-hábito e memória-acontecimento. Posteriormente, apresentamos a perspectiva e os procedimentos metodológicos do trabalho, enfocando a escrita autobiográfica como dispositivo formativo em educação, os processos de autobiografização e heterobiografização. A partir dessas escritas autobiográficas, dos estudantes, refletimos sobre as pedagogias emergentes das experiências acontecidas, tecidas e entre-tecidas. Por fim, visualizamos a presença e a emergência de pedagogias com sinais, traços e contornos marcados de indignação, outreidade e cidadania.

\section{Das ocupações: duração,} memória-hábito e memóriaacontecimento

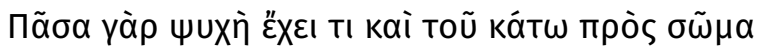

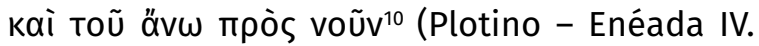
8:8)

Depois de 65 dias de muita luta, olho pra trás e percebo o quanto a minha percepção de universidade mudou. O CAV, que antes era somente o local para início e término da minha graduação, se tornou o berço da minha formação social. Me fez repensar as relações humanas, a me importar com o outro, a pensar numa universidade do futuro que não será para mim, mas para todos que desejam e têm o direito de desfrutar disso. O CAV hoje representa muito mais para todos nós que participamos desse processo de

10 "Nem tudo o que ocorre em qualquer parte da alma é logo conhecido por nós, pois, para que tal conhecimento se dê, a coisa tem de estar presente para a alma inteira" (PLOTINO, 2000, p. 94). construção. Em 10 anos de centro e 3 anos em que estou dentro da graduação, sinto os 65 dias como o tempo necessário para conhecer o CAV de verdade, perceber cada tijolo, cada espaço, cada detalhe e ter a certeza de que aquele lugar deve ser reconhecido como nossa segunda casa, que devemos preservar e lutar para que próximas gerações tenham acesso a um espaço acadêmico cada vez melhor, paritário e representativo. Hoje sinto orgulho do centro no qual faço parte, e lembrarei com muito apreço da nossa força e resistência diante de todas as repressões sofridas para garantir que direitos sejam mantidos e não extintos. É nítido e muito importante que a luta deve continuar independentemente dos ganhos adquiridos com o passar dos anos, mas que nossos filhos, netos e bisnetos possam estudar numa universidade melhor e paritária em todos os sentidos, isso porque o CAV mostrou sua existência e resistiu em nome dos direitos do povo. (M.G., 2016, linhas 103-122)

Quanto tempo durou a ocupação? A vida inteira, se experienciada com a "alma inteira". Os relatos autobiográficos dos estudantes que participaram do CAV r_Existe são uníssonos ao reportarem que os 65 dias $^{11}$ em que o campus foi por eles ocupado, com uma certa ruptura da rotina ${ }^{12}$ acadêmica, e a instauração de outra rotina, repleta de vivências educativas não formais, oportunizaram aprendizagens diversas em espaços organizados, mediados e mobilizados pelos próprios ocupantes, alguns servidores sensiveis às suas reivindicações e à comunidade empobrecida que habita o entorno da universidade, a qual tanto abraçou a luta, como foi abraçada por ela.

11 Na contabilidade dos dias da ocupação, por vezes, alguns participantes atribuem 68 dias ou mais, considerando ainda os dias de mobilização que antecederam a ocupação propriamente dita.

12 As palavras "rotina" e "ruptura" possuem a mesma origem etimológica. Ambas advêm do latim rupta que designam "caminho, direção, rumo" (CUNHA, 2001, p. 691-692). Ou seja, há um fecundo paradoxo semântico no termo "rotina": a) que pode ser compreendido como caminho já aberto e já traçado, percorrido ordinariamente. Mas também pode significar b) ruptura, novo caminho aberto, nova rota. 
Essa nova rotina, planejada, acordada e revista, diariamente, rompeu com a demarcação de um tempo mensurado e homogêneo, predeterminado pelos currículos acadêmicos, e proporcionou um certo "tempo fora do tempo"; vivências que não cabiam num currículo comum, pois tratava-se de um "currículo vivo" (curriculum vitae). Tal percepção foi evidenciada quando, ao final da experiência da ocupação, o grupo de ocupantes manifestou seu interesse em escrever um livro ${ }^{13}$ que se intitularia Dez anos em sessenta e oito dias. Afinal, naquele ano de 2016, o campus da UFPE, em Vitória de Santo Antão (PE), estava celebrando dez anos de existência. Ou seja, tal título se reporta a uma nuance qualitativa do tempo da experiência pedagógica na universidade. Além disso, o título do almejado livro expressa um paradoxo da experiência temporal: seria possivel viver dez anos em sessenta e oito dias na universidade?

O estabelecimento de relações entre a $d u$ ração qualitativa do tempo experienciado pelos humanos e memória não é novo. Plotino ${ }^{14}$ afirmava que para que um conhecimento se dê de forma integral, na alma humana, deve

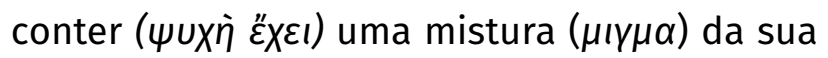
porção corpórea ( $\pi \rho \grave{\varsigma} \sigma \tilde{\omega} \mu \alpha)$ com sua porção

13 Imbuídos pelo ímpeto da produção desse livro a maioria dos estudantes que participaram do movimento CAV r_Existe redigiram diversas narrativas autobiográficas das suas experiências e (acon)tecimentos. Todavia, o livro, até o presente, não foi publicado. Seis ocupantes concordaram em oferecer seus escritos para a construção deste artigo, sendo que uma delas se disponibilizou, inclusive, a ser coautora deste trabalho.

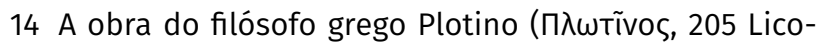
pólis, Egito - 270 D.C.) chegou até nós pelo seu discípulo Porfirio, que publicou um livro sobre a vida de seu mestre. Além disso, ele também organizou os 54 tratados de Plotino na obra As Enéadas, composta por seis livros. Assim soubemos que Plotino pertencia a uma família romana que se estabeleceu no Egito. Foi estudar em Alexandria e, aos 28 anos, consagrou-se, exclusivamente, à filosofia. Cultivava-se, ali, há muito tempo, um forte ambiente científico e filosófico, destacando-se os estudos das obras de Aristóteles e Platão. Plotino é considerado um dos maiores representantes do neoplatonismo. divina ( $\pi \rho \grave{s}$ voũv). Importante ressaltar que a concepção metafísica plotiniana da vida psicológica do sujeito não se restringia a um escopo individualizante, haja vista que sua porção divina estava ligada à alma do mundo (vous).

$\mathrm{Na}$ modernidade, Henri Bergson ${ }^{15}$ tomou como uma de suas bases filosóficas a metafísica de Plotino, seu filósofo preferido, problematizando-a e redimensionando-a. Assim, Bergson construiu um potente arcabouço teórico sobre os conceitos de "memória" e "duração".

Para o filósofo, o tempo é o tecido que compõe a vida psicológica (BERGSON, 2010, p. 4). Contudo, o tempo real da experiência humana - a duração - não pode ser medido porque "a linha que medimos é imóvel, o tempo é mobilidade. A linha é o feito, o tempo é o que se faz e mesmo o que faz com que tudo faça" (BERGSON, 1984, p. 102). Portanto, "se o tempo é uma linha, somos novelo. Passado, presente e futuro não são tempos que se sucedem, mas se sobrepõem" (MACHADO, 2012, p. 132). Ou seja, ao analisar a experiência humana, incluindo a pedagógica, como um caminho linear, como um espaço a ser percorrido, estaríamos buscando mensurar o incomensurável ao tomar o tempo, tecido da vida psicológica profunda, como uma dimensão do espaço.

Nesse sentido, Bergson classifica a memória em duas formas, diferenciando-as pelo grau e natureza de seu envolvimento com a vida psíquica: a memória que "tem todas as características do hábito" e a memória que “imprimiu-se necessariamente de imediato na

15 Ao longo de sua vida (1859-1941), o pensador francês Henri Louis Bergson produziu uma consistente, profunda e ampla obra filosófica. Ele estudou na Ecole Normal Supérieure de 1877 a 1881 e passou os 16 anos seguintes como professor de filosofia. Em 1900, tornou-se professor no Collège de France. O filósofo entrou na Academia francesa em 1914, ganhando, inclusive, o Prêmio Nobel de Literatura em 1928. Bergson se constituiu como um grande filósofo porque criou novos conceitos que "dão às coisas uma verdade nova, uma distribuição nova, um recorte extraordinário" (DELEUZE, 1999, p. 125). 
memória [...] como um acontecimento" (BERGSON, 2010, p. 86). A primeira pode ser nomeada de "Memória-Hábito" (BOSI, 1994, p. 48-51) e a segunda como "Memória-Acontecimento" (MACHADO, 2012, p. 128).

A "Memória-Hábito" está mais associada ao nosso eu superficial ( $\pi \rho \grave{s} \sigma \tilde{\omega} \mu \alpha)$. Ela possui as características de um hábito e, portanto, é adquirida pela repetição de exercícios habituais do corpo, geralmente associada aos mecanismos motores e está ocupada das necessidades ordinárias da vida, afinal, "basta o hábito e, no mais das vezes, basta-nos ir a esmo para dar à sociedade o que ela espera de nós" (BERGSON, 1978, p. 15). Bergson ilustra esse tipo de memória por meio da necessidade de se "aprender" uma lição:

A lembrança da lição, enquanto aprendida de cor, tem todas as características de um hábito. Como o hábito, ela é adquirida pela repetição de um mesmo esforço. Como o hábito, ela exigiu inicialmente a decomposição, e depois a recomposição da ação total. Como todo exercício habitual do corpo, enfim, ela armazenou-se num mecanismo que estimula por inteiro um impulso inicial, num sistema fechado de movimentos automáticos que se sucedem na mesma ordem e ocupam o mesmo espaço [...] A lembrança da lição aprendida, mesmo quando me limito a repetir essa lição interiormente, exige um tempo bem determinado, o mesmo que é necessário para desenvolver um a um, ainda que em imaginação, todos os movimentos de articulação requeridos: portanto não se trata de uma representação, trata-se de uma ação. (BERGSON, 2010, p. 86)

A "Memória-Acontecimento", por sua vez, está ligada ao nosso eu profundo. Trata-se de uma experiência pessoal de encontro com a alma do mundo (vous). Atingimo-la por meio de uma reflexão aprofundada. Todavia,

Os momentos em que voltamos a ser donos de nós próprios são raros, e é por isso que raramente somos livres. Na maior parte do tempo, vivemos exteriormente a nós mesmos, não per- cepcionamos do nosso eu senão o seu fantasma descolorido, sombra que a pura projeção projeta no espaço homogêneo. A nossa existência desenrola-se, mais no espaço do que no tempo: vivemos mais para o mundo exterior do que para nós; falamos mais do que pensamos; 'somos agidos' mais do que agimos. Agir livremente é retomar a posse de si, é situar-se na pura duração. (BERGSON, 2011, p. 173-174)

Dessa forma, parece-nos que os participantes desta pesquisa situam seus relatos num âmbito de experiências existenciais profundas que passam a ressignificar suas experiências acadêmicas. Em outras palavras, como veremos a seguir, as narrativas autobiográficas dos estudantes que ocuparam a universidade, sugerem evidenciar, predominantemente, memórias-acontecimentos associadas a aprendizados que duram, extrapolando sentidos estritamente pessoais e curriculares, resignificando as experiências pedagógicas universitárias conectadas a uma perspectiva mais profunda e ampla.

Tais acontecimentos duram porque se inscreveram como marcas nas almas humanas. Costa Carvalho (2009) ressalta com precisão a frutífera semântica da origem etimológica que levou Bergson a conceitualizar a duração:

Consideramos, ainda, digno de nota que, em termos etimológicos, no verbo latim durare - de onde provêm quer o termo francês durée, quer os ingleses duration e durance, quer o português duração -, se encontrem presentes significados como 'endurecer', 'fortificar', 'subsistir' e 'perseverar' que, em termos filosóficos, remetem para uma metáfora com que Bergson se refere à 'duração'. A 'dentada'16 da duração deixa nos seres a marca da permanência temporal, endurece-os e fortifica-os, permitindo-lhes superar uma existência enquanto justaposição inconsequente de momentos desligados e autônomos e conferindo-lhes a perseverança do estofo mais resistente e substancial de todos: 0 tempo. (COSTA CARVALHO, 2009, p. 4)

16 "A duração real é aquela que morde as coisas e nelas deixa a marca de seus dentes" (BERGSON, 2005, p. 50). 
Assim, a seguir, apresentaremos o escopo teórico-metodológico que sustenta o uso de narrativas autobiográficas de estudantes que participaram do movimento CAV r_Existe para que se analisem as pedagogias que emergem pela duração das experiências da ocupação em uma universidade federal.

\section{A escrita autobiográfica como dispositivo formativo em educação: autobiografização e heterobiografização}

A escrita autobiográfica é um recurso metodológico que transcende o espaço e o tempo homogêneo da rotina ordinária dos currículos das instituições educacionais. Por esse motivo, pode ser considerada como privilegiado dispositivo reflexivo e formativo em educação, pois incentiva os sujeitos a refletirem e registrarem as marcas que duram em suas almas, sistematizando-as nalgum documento, seja ele escrito, desenhado ou midiatizado. Podemos entendê-la, portanto, como dispositivo formativo, uma vez que um de seus pressupostos fundadores dá conta de que:

[...] a escrita de si propiciaria ao ator-autor da história a possibilidade de construir uma versão satisfatória de si mesmo, mediante a reflexão sobre sua experiência, no ato de narrar a história de sua vida e/ ou de sua formação. (PASSEGGI, 2008, p. 103-104)

Além disso, a narrativa de si e a escuta da narrativa de outrem oportunizam a tessitura das tramas que compõem a vida do sujeito, com aproximação e distanciamento com os enredos dos outros, também nos âmbitos coletivos e societais, uma vez que, conforme Machado:

[...] ao narrar, ao compor novamente a trama de suas vidas, o narrador revê a si mesmo e o mundo do qual participa. Ele se reconhece, se respeita. Etimologicamente, a palavra respeito vem do latim res-pectare (CUNHA, 2001, p. 678), ou seja, re-espectar, rever. Ou seja, ao narrar-se os entrevistados entrelaçam suas histórias, como artistas, de uma maneira singular que thes propicia um tempo e um espaço de re-olhar para si mesmo, reconhecendo-se. (2005, p. 25)

Afinal, enquanto tece as tramas do narrado, o narrador se torna o próprio tecido, ensinando e aprendendo, ao mesmo tempo, pelo ir e vir dos registros de sua memória. "A experiência narrativa oferece ao narrador a matéria narrada, quer esta experiência seja própria ou relatada, que é sempre nova e singular, pois é artesanalmente comunicada" (MACHADO, 2005, p. 60). Sendo assim, no âmbito deste trabalho, desenvolvemos com os participantes do movimento CAV r_Existe um processo de registro e escritas autobiográficas, compreendidas enquanto um dispositivo de escrita-pesquisa-formação, ${ }^{17}$ que se constitui em uma atividade de produção do ato de narrar, isto é, de autobiografização. Trata-se de um processo que contempla uma abordagem qualitativa, de cunho narrativo, que possibilita inter(pret) ações por meio de uma "hermenêutica prática, um quadro de estruturação e significação da experiência por intermédio do qual o indivíduo atribui-se uma figura no tempo, ou seja, uma história que ele reporta a um si mesmo" (DELORY-MOMBERGER, 2014, p. 27).

Outrossim, destacamos que a produção autobiográfica dos participantes desta investigação também se constituiu em uma atividade de recepção do ato de narrar, ou seja, de heterobiografização, pois a forma das escritas de si também foram produzidas a partir das experiências das narrativas do outro, mediante uma atitude de empatia e confronto com a narrativa de outrem (idem, p. 57-58).

17 Ao operarmos com as narrativas autobiográficas, enquanto uma abordagem qualitativa e desde um movimento de pesquisa-formação, dialogamos com Passeggi (2010, 2015), Passeggi; Nascimento; Oliveira (2016) e Delory-Momberger (2014). 
Os textos escritos pelos estudantes do movimento CAV r_Existe, utilizados neste artigo, foram produzidos, coletivamente, a partir de oficinas de escrita de narrativas autobiográficas sobre as experiências vivenciadas no movimento. Tais oficinas foram realizadas nos últimos dias da ocupação do campus universitário, quando o coletivo decidiu produzir um livro com relatos. Embora o referido livro ainda não tenha sido publicado, reconhecemos nesse material um potente dado empírico para a produção deste trabalho. Para tanto, entramos em contato com todos os dez estudantes que participaram da oficina e produziram narrativas escritas. Obtivemos respostas de seis autores, que nos autorizaram a utilizar seus textos. Uma autora, inclusive, se tornou coautora deste artigo, participando de todo processo de sua produção.

Para fins de identificação dos autores das escritas autobiográficas utilizamos as iniciais de seus nomes, curso, título da escrita e número de linhas por arquivo, conforme a Tabela:

Tabela 1 - Escritas autobiográficas sobre ocupação

\begin{tabular}{c|c|c|l|c|} 
Arquivo & $\begin{array}{c}\text { Iniciais do } \\
\text { Nome }\end{array}$ & \multicolumn{1}{|c|}{ Curso } & \multicolumn{1}{c|}{ Título da Escrita } & $\begin{array}{c}\text { No de } \\
\text { linhas }\end{array}$ \\
\hline N_01 & R.L.S & Educação Física & Escrita (Auto)biográfica & 101 \\
N_02 & M.J.S. & Ciências Contábeis & Construção do livro da ocupação & 254 \\
N_03 & R.J.M. & Saúde Coletiva & Livro do CAV r_Existe & 95 \\
N_04 & R.S.S. & Educação Física & Uma Vida de Lutas & 62 \\
N_05 & E.C.L. & Educação Física & Sonhamos & 40 \\
N_06 & M.G. & Nutrição & Construção do livro da ocupação & 357
\end{tabular}

Fonte: elaborada pelos autores, 2020.

Sob a perspectiva de análise desse material empírico, evidenciamos um processo de confecção intelectual artesanal (WRIGHT-MILLS, 1972), a partir do entrelaçamento das tessituras das intrigas (RICOEUR, 2010, p. 57) que compõem as experiências de lutas de estudantes universitários pela educação. Portanto, ao reconhecer que "o tempo se torna humano na medida em que está articulado de modo narrativo, e a narrativa alcança sua significação plenária quando se torna uma condição da existência temporal" (idem, p. 93), realizamos, a seguir, inter(pret)ações, sob uma perspectiva hermenêutica, que evidenciam reflexões sobre as pedagogias emergentes.
As pedagogias emergentes: das experiências acon-tecidas às escritas entre-tecidas

Em nossos estudos com as juventudes, tentamos contribuir com a potencialidade de uma escuta sensivel, aberta, a(fe)tiva, ética e aprendente que pode captar múltiplas pedagogias emergentes. Como já dito anteriormente, no âmbito deste trabalho, por meio de uma hermenêutica prática, sistematizamos, didaticamente, pedagogias emergentes a partir das escritas autobiográficas de seus participantes. Abaixo, apresentaremos uma tríade que emergiu desse processo: pedagogia da indignação, 
pedagogia da outreidade e pedagogia da cidadania.

Cabe ainda ressaltar que as pedagogias, aqui apresentadas, não devem ser compreendidas ou analisadas de modo isolado, como categorias estanques. As três pedagogias apresentadas se constituem em uma sistematização de reflexões, a partir de processos de autobiografização e heterobiografização, que transversalizam e extrapolam qualquer movimento de classificação reducionista.

\section{Pedagogia da indignação}

Sempre recusei os fatalismos. Prefiro a rebeldia que me confirma como gente e que jamais deixou de provar que o ser humano é maior do que os mecanismos que o minimizam (FREIRE, 1996, p. 115)

Mas tudo se mostrava tão mais grandioso que somente ir contra ou tentar mudar a opinião dos governantes. Acredito que grande parte estava bem mais preocupada em demonstrar sua insatisfação, sair da sua zona de conforto, e mesmo que a situação não saísse como desejássemos, não ficariamos com sentimento de frustração e sim de que lutamos, lutamos da forma que podíamos e no tempo que tivemos, de forma diferente cada um, claro, mas todos com o mesmo sentimento de que não ficaríamos calados demonstrando-nos inconformados com a realidade em que vivemos, e que desejamos que seja transformada. Foi e é o despertar de uma juventude preocupada com o futuro, com o seu e com o dos que virão, que não quer só assistir, mas participar ativamente dessa transformação, buscando garantir o direito dos que mais precisam e são marginalizados em nosso país (R.L.S., 2016, linhas 56-66, grifos nossos).

Esse testemunho é significativo no que tange ao sentido mobilizador dos a(u)tores da ocupação. Mesmo diante da ameaça da retirada de direitos e recursos para as políticas públicas por um Estado "grandioso", os sentimentos de "indignação-amor-incompletude" levou um grupo de estudantes universitários a se or- ganizar em um movimento de ocupação para despertar uma juventude "preocupada com o futuro" e partícipe de um processo de transformação da universidade e da sociedade, em favor da garantia de direitos, especialmente, dos mais empobrecidos e marginalizados do país. A indignação e a rebeldia se configuraram, portanto, como motores e combustíveis para transformações de inéditos viáveis.

A pedagogia da indignação, aqui, guarda relação direta e proximal não somente com o título homônimo da obra, mas sobretudo com a perspectiva dialética de Freire (2000) em que não se pode compreender a indignação separada do seu oposto antagônico que é o amor e a esperança. Ana Maria de Araújo Freire ao referenciar a obra e a vida de Paulo Freire, diz que ele:

[...] pôde sentir a raiva necessária, profunda e intensa para perceber, constatar e lutar por inéditos viáveis, como dar voz ao povo, conscientizá-los de que todos e todas são sujeitos da história e não apenas objetos nela. [...] determinou a sua luta destemida contra as relações e as condições de opressão geradas dentro dele pelo sentir profundo da indignação-amor-incompletude humana sobre os quais, incidindo as suas reflexões mais profundas, nasceu a denúncia-amor-esperança. (FREIRE, 2018, p. 262)

Nesse sentido, portanto, a indignação "necessária, profunda e intensa" com uma realidade levou um grupo de estudantes universitários a sair de sua "zona de conforto" e a organizar um conjunto de experiências existenciais profundas, em uma ambiência acadêmica, permeada por ações educativas para transformação de si, do outro e do mundo, como formas de resistência, num devir de "denúncia-amor -esperança" que visava "despertar" a universidade e a sociedade:

Sabíamos que a ocupação sozinha não conseguiriam mudar a realidade de nosso país nem barrar uma PEC temos maturidade suficiente para entender isso, na minha opinião ela sur- 
ge com o desejo de ser um primeiro passo para despertar a comunidade acadêmica, e para desperta o movimento estudantil e uma sociedade que ainda dorme. (R.L.S., 2016, linhas 42-45)

As narrativas autobiográficas dos ocupantes evidenciam que o movimento CAV r_Existe buscou despertar a comunidade acadêmica e todo seu entorno, por meio de uma ocupação permeada por ações educativas que visavam convidar as pessoas a refletir sobre o papel da universidade e do universitário, especialmente no sentido de "formar cidadãos com capacidade crítica para compreender e modificar a sociedade tendo em vista o alcance de uma sociedade mais justa, menos desigual" (M.J.S., linhas 15-16).

Para tanto, a participação nessa luta foi exigente. Uma pedagogia da indignação foi sendo vivenciada, levando os participantes do movimento a abrir mão de valores individuais, por prioridades baseadas em valores coletivos:

[...] a nossa luta foi, é e será por todos eles que se sacrificaram todos os dias para nos dar a vida mais digna possivel. Naquele momento precisávamos elencar prioridades e fazer sacrificios. Ficar longe da família foi um deles. (M.G., 2016, linhas 212-215)

E ainda não eram somente nossos interesses que nos fazia persistir, mas o pensar nos que ainda estão por vir, com todos seus planos, sonhos, medos [...] é também por eles que lutamos. (R.L.S., 2016, linhas 46-49)

Assim, a experiência da ocupação vai na contracorrente de uma lógica de um poder de domesticação alienante, daquilo que Freire (1996, p. 114) denomina de "burocratização da mente". Uma experiência intensa de um movimento contra-hegemônico a favor de um inconformismo do sujeito e dos coletivos, contra as formas de acomodação diante das situações consideradas fatalistamente imutáveis (idem, p. 114). As narrativas dos participantes refletem experiências que afirmam processos educacio- nais que reconhecem os sujeitos como autores sociais que transformam o curso da história, não se conformando com currículos e discursos impregnados de determinismo. Em outras palavras, uma pedagogia da indignação foi experienciada pelos participantes do movimento CAV r_Existe, pois eles reconheceram que "mudar é dificil mas é possivel" (FREIRE, 1996, p. 79).

\section{Pedagogia da outreidade}

Uma das tarefas mais importantes da prática educativo-crítica é propiciar as condições em que os educandos em suas relações uns com os outros e todos com o professor ou a professora ensaiam a experiência profunda de assumir-se. Assumir-se como ser social e histórico, como ser pensante, comunicante, transformador, criador, realizador de sonhos, capaz de ter raiva porque capaz de amar. Assumir-se como sujeito porque capaz de reconhecer-se como objeto. A assunção de nós mesmos não significa a exclusão dos outros. É a 'outredade' do 'não eu', ou do tu, que me faz assumir a radicalidade de meu eu. (FREIRE, 1996, p. 41)

A palavra que poderia definir esse processo de tornar-se um ocupante seria 'descoberta'. É autoconhecimento, é descobrir muita força e resistência dentro de si, é aprender a reconhecer que a dor do outro também é a sua, que o coletivo está acima do individual e que a soma das forças desse coletivo é a verdadeira chave para uma sociedade que valorize e trate todos os indivíduos de forma igualitária. (M. G., 2016, linhas 26-31)

As narrativas autobiográficas dos ocupantes explicitam também um processo de aprimoramento humano, de reconhecimento de si pelo reconhecimento do "Outro como um legitimo Outro na convivência" (MATURANA, 1998, p. 23). As ações promovidas pelo movimento CAV r_Existe favoreceram convivências humanas que levaram seus participantes a reverem seus valores, assumindo-se como seres sociais e históricos, imbuídos do sentimento de empatia, capazes de compaixão, ou seja, de sen- 
tir com o outro suas dores, que passam a ser também suas. Trata-se da emergência de uma pedagogia da outreidade que favorece uma ascese $^{18}$ pessoal para assunção de um assumir-se radicalmente a si mesmo como um ser "pensante, comunicante, transformador, criador, realizador de sonhos", inclusive de sonhos coletivos, de inéditos viáveis.

Dentre as pedagogias criadas por Paulo Freire, não se encontra uma, especificamente, sobre outreidade. Todavia, como referenciamos na epígrafe acima, em sua Pedagogia da Autonomia, o patrono da educação brasileira utiliza tal conceito para se referir à assunção da radicalidade de um "eu" pelo encontro de um "tu". Nesse sentido, trabalhos acadêmicos sobre a obra freiriana, como o de Souza (2013, p. 137), defendem a tese da elaboração de um currículo para a outreidade, como prática da liberdade, por meio do diálogo, negando a "coisificação do outro".

As narrativas dos ocupantes entre-tecem experiências e evidenciam memórias-acontecimentos que revelam uma pedagogia da outreidade, alheia aos caminhos - curricula - formais e institucionais dos projetos político-pedagógicos idealizados para os cursos de graduação. Por uma intensa pré-ocupação com o futuro, de si e dos outros, as escritas autobiográficas dos ocupantes parecem explicitar um currículo vivo - curriculum vitae -, fora do currículo formal, ressignificando a experiência acadêmica, fazendo emergir uma pedagogia que foi capaz de criar

[...] uma grande família em que as relações humanas e sociais do CAV passaram a ter uma outra dimensão, já que o Outro passou a ter valor. A luta não era pessoal, mas, sobretudo, pelos Outros, pelas futuras gerações, pelas famílias, pela comunidade, pela sociedade brasileira. ( $M$. J.S., 2016, linhas 66-69)

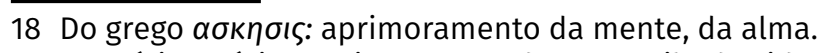
Exercício, prática, treino. Um modo, um estilo de vida. (Liddell \& Scott, s/d, p. 124).
Nesse processo, inclusive, a figura dos professores passou a ser reconhecida de forma paradoxal, entre "decepção e admiração", também pela capacidade (ou falta dela, em alguns casos!) de empatia dos docentes para com os ocupantes.

E no que diz respeito aos professores surgiu um misto de decepção e admiração. Uns nos incentivaram a permanecermos na luta, nos auxiliando nas formações, doando alimentos, chegando a dizer que se sentiam jovens novamente ao nos verem fazendo parte daquela luta, admirando aquele acontecimento vindo da parte dos estudantes em tempos tão dificeis, onde a luta e resistência são tão necessárias, onde a liberdade de expressão e democracia se mostram tão ameaçadas. Ao mesmo tempo, outros, que muitas vezes nos incentivaram com suas aulas, mostraram-se contra, nos ameaçando com faltas e reprovações, chamando de bobeira o que estávamos fazendo, nos demonstrando que eles só possuíam um belo discurso, que infelizmente não se aplicava na prática. (R.L.S., 2016, linhas 83-92)

Ao contemplar a outreidade dos seus mestres, os estudantes parecem respeitar e valorizar a coerência entre o que se diz e o que se faz, entre o discurso e a realização, entre a teoria e a prática, afinal "ensinar exige a corporeificação das palavras pelo exemplo" (FREIRE, 1996, p. 38).

0 reconhecimento do outro enquanto um legítimo implica também em poder percebê-lo como diferente, alheio, distinto, adversário. Assim, por exemplo, os participantes do movimento CAV r_Existe foram denominados por muitos como "invasores":

Mas a tristeza surge, especialmente, por ver que muitos preocupavam-se com coisas tão pequenas para 'difamar', de alguma forma, o movimento, mostrando-se, aparentemente, não muito preocupados com a situação do nosso país e não sentindo a Universidade como sua, porque se sentissem não chamariam os ocupantes de invasores, como alguns chegaram a 
dizer. Afinal, como invadiríamos uma coisa que é nossa? (R.L.S., 2016, linhas 33-38)

Mesmo que entristecidas, as narrativas autobiográficas dos participantes evidenciam vivências de uma pedagogia da outreidade que propiciou uma ascese pessoal e coletiva que foi, progressivamente, ressignificando os sentidos de suas vidas e da própria universidade:

Com o passar dos dias, a ocupação foi se tornando algo além do solo de resistência, o sentimento de pertencimento fez reconhecer que 0 CAV é a nossa casa e nossos amigos são a nossa família. Em meio às dificuldades, à saudade e ao cansaço, descobrimos, entre nós, que algo muito forte nos unia e que esse elo é o que nos manteve juntos durante toda a nossa permanência. Reconhecemos, entre pessoas que eram apenas mais um nos corredores da universidade, irmãos, filhos, mães, primos. (M.G., 2016, linhas 217-223)

Assim, a experiência da ocupação vai na contracorrente de processos curriculares estritamente formais e institucionais, estabelecendo uma formação humana, ética e cidadã. Afinal, as narrativas dos ocupantes evidenciam o diálogo, a amorosidade e a coletividade como importantes valores que brotaram da ( $r$ ) existência e da luta pelo direito à educação.

\section{Pedagogia da cidadania}

Ninguém liberta ninguém, ninguém se liberta sozinho: os homens se libertam em comunhão (FREIRE, 1981, p. 87).

Os estudantes pertencentes ao movimento das ocupações, chamados de 'ocupantes' do aparelho público, no caso, a universidade, foram construindo sua cidadania a partir do sentimento de pertencer a um todo, o país, e defendê-lo, valorizando também as lutas dos que os precederam e se adiantando no tempo, deixando legado aos futuros jovens. (R.L.S., 2016, linhas 70-76)

Por fim, entre-tecemos memórias-acon- tecimentos de ocupantes, que refletem um processo de convivência, que possibilitou a construção de um pertencimento às lutas pela liberdade dos oprimidos, por meio da emergência de uma pedagogia da cidadania. Reconhecendo a universidade como um "aparelho público", os participantes do movimento CAV r_Existe promoveram processos de problematização e conscientização dos papéis sociais da universidade e dos diversos atores que a compõem, direta ou indiretamente, por meio de ações educativas, de inéditos viáveis, numa perspectiva freiriana. A propósito,

A educação com vistas à cidadania é o objetivo de Freire desde o começo de sua atuação como educador. A cidadania em Freire é compreendida como apropriação da realidade para nela atuar, participando conscientemente em favor da emancipação. (HERBERT, 2018, p. 77)

Ao contemplarem as intensas convivências cotidianas, experienciadas durante o tempo da ocupação, os participantes revelam, por meio de seus escritos autobiográficos, que dentre os principais aprendizados que duram, e seguem reverberando em suas vidas, estão os valores da coletividade, da comunidade e da cidadania. São tais valores que fazem, por exemplo, o ocupante E.C.L. afirmar: "sou o que sou, pelo que somos" (2016, linha 40).

Nesse sentido, é importante destacar que os traços de uma pedagogia da cidadania emergiram de diversas ações que problematizaram as funções do Estado, da República e de seus equipamentos públicos, principalmente a universidade pública. Dentre essas ações, as atividades pedagógicas com a comunidade empobrecida, em torno do campus da UFPE, em Vitória de Santo Antão, mereceram destaque em suas narrativas. Uma agenda permanente de ações educativas envolvendo, principalmente, mulheres e crianças, abriram as portas, pela primeira vez, a esses cidadãos, vizinhos da universidade ocupada. 
Afinal, na opinião dos ocupantes, é função da universidade pública "a comunicação direta com a comunidade através da prestação de serviços diretos de pesquisa, extensão e do desenvolvimento das comunidades que se encontre em torno da mesma" (M.J.S, 2016, linhas 17-19). Além de trazer essa definição, a mesma narrativa nos lembra que, muitas vezes, a educação pública "não dialoga conforme suas condições e obrigações deixando assim a mesma afastada pelos muros que não são apenas físicos" (M.J.S, 2016, linhas 17-24).

Tal pedagogia da cidadania se dá no sonho coletivo como motor de suas práticas e de suas vidas. Trata-se de uma utopia que habita na tensão entre "a denúncia de um presente tornando-se cada vez mais intolerável e de um futuro a ser criado, construído, política, estética e eticamente, por nós, mulheres e homens" (FREIRE, 2003, p. 91).

Sonhamos com o dia em que o filho do pobre e o filho do rico estejam estudando todos juntos em escolas, de fato, públicas, gratuitas e de qualidade, sem muros, sem grades, com uma gestão participativa e professores valorizados, humanizados, ou ainda melhor, sonhamos com o dia em que não haja classificação entre ricos nem pobres. E mais que isso, sonhamos com uma sociedade que se reconheça enquanto plural e de fato democrática, que não se cale diante de nenhum ataque à dignidade do povo. (E.C.L, 2016, linhas 11-16)

Assim, a experiência da ocupação também vai na contracorrente de uma formação universitária estritamente tecnicista e elitista, com vistas ao mercado de trabalho. Afinal, as narrativas dos participantes explicitam o sonho e o compromisso de luta por uma educação libertadora, plural, diversa, democrática e socialmente referenciada. Por esse sonho, ocuparam o espaço público da universidade. Pelo mesmo sonho, parecem almejar seguir se ocupando com as lutas sociais em prol da dignidade de todos.

\section{Considerações finais}

Objetivamos, por meio deste trabalho, reconhecer e analisar as pedagogias emergentes, advindas de escritas autobiográficas de universitários, em um movimento de ocupação. Para tanto, metodologicamente, utilizamos narrativas autobiográficas de ocupantes do movimento CAV r_Existe.

A partir desse material empírico, analisado hermeneuticamente, evidenciaram-se três pedagogias emergentes das memórias-acontecimentos, entre-tecidas, dos ocupantes. Tal tríade pedagógica se mostrou complementar e articulada em um continuum: as narrativas explicitam que a partir de uma pedagogia da indignação se cria um movimento baseado na descoberta, pela convivência, de uma pedagogia da outreidade, que faz os sujeitos se aprimorarem humanamente (ascese), a partir do reconhecimento do outro como um legítimo outro e da coletividade, levando-os a uma pedagogia da cidadania, que se consubstancia num sentimento de pertencimento às causas populares, sonhos coletivos, utopias, ressignificando suas vidas, transformando a educação e a sociedade, por meio de inéditos viáveis.

Constata-se que as experiências existenciais, propostas pelo movimento CAV r_Existe, duram nas vidas daqueles que se autobiografaram, demonstrando a potência e a profundidade das vivências educativas de ocupação, que seguem reverberando no presente, reinventando novos modos de fazer universidade, novas formas de lutar, de se viver pessoal e coletivamente.

Nesse sentido, cabe pontuar que, embora a PEC no 241/55 de 2016 tenha sido aprovada e o livro não tenha sido publicado ainda, para além da dimensão formativa, a ocupação trouxe muitos frutos no âmbito da luta estudantil para a universidade. Diretórios Acadêmicos de estudantes foram criados, os já existentes fo- 
ram revigorados e o Diretório Central dos Estudantes da UFPE foi recriado. Além disso, duas das principais pautas da ocupação foram alcançadas, nomeadamente o Novo Estatuto e o Novo Regimento Geral da universidade.

Por fim, destacamos ainda a necessidade de novas investigações sobre pedagogias emergentes de lutas sociais, especialmente na educação, amparadas nas bases metodológicas e epistemológicas das narrativas autobiográficas. Oxalá, nestes tempos sombrios, possamos colocar em prática o que aprendemos com os ocupantes, (re)criando e (re)inventando novas formas de se (com)viver, por meio de uma indignação amorosa, capaz de reconhecer o outro como um legítimo outro, em gestos esperançados, imersos em uma cidadania planetária.

\section{Referências}

BERGSON, Henri. As Duas Fontes da Moral e da Religião. Rio de Janeiro: Zahar, 1978.

BERGSON, Henri. O Pensamento e o Movente. In: BERGSON, Henri. Cartas, Conferências e outros escritos. São Paulo: Abril Cultural, 1984, p. 99-152 (Coleção Os Pensadores).

BERGSON, Henri. A Evolução Criadora. São Paulo: Martins Fontes, 2005.

BERGSON, Henri. Matéria e Memória. São Paulo: Martins Fontes, 2010.

BERGSON, Henri. Ensaio sobre os Dados Imediatos da Consciência. Lisboa: Edições 70, 2011.

BOSI, Ecléa. Memória e Sociedade: Lembranças de Velhos. São Paulo: Companhia das Letras, 1994.

CAVALCANTI, Ana Claudia Dantas. Movimento Ocupa em Pernambuco: por um diálogo estimulado na Educação. Educação \& Realidade, Porto Alegre, v. 44, n. 3 , 2019. Disponivel em: http://dx.doi.org/10.1590/2175623680861. Acesso em: 14 maio 2020.

COSTA CARVALHO, Magda. A noção de "natureza criadora" no evolucionismo metafísico de Henri Bergson: estrutura e alcance de um projecto bio- filosófico. 2009. 210 f. Tese (Doutorado em Filosofia) - Universidade dos Açores, Ponta Delgada, 2009.

CUNHA, Antônio Geraldo da. Dicionário Etimológico Nova Fronteira da Língua Portuguesa. Rio de Janeiro: Nova Fronteira, 2001.

DELEUZE, Gilles. BERGSONISMO. São Paulo: Editora 34, 1999.

DELORY-MOMBERGER, Christine. Biografia e Educação: figuras do indivíduo-projeto. Tradução e revisão científica Maria da Conceição Passeggi, João Gomes da Silva Neto, Luis Passeggi. 2a ed. Natal: EDUFRN, 2014.

FREIRE, Ana Maria Araújo. Pedagogia da indignação: cartas pedagógicas e outros escritos. Interface, Botucatu, v. 5, n. 8, p. 147-152, fevereiro de 2001. Disponivel em: http://www. scielo.br/scielo.php?script=sci_arttext\&pi$d=S 1414-32832001000100016 \& \operatorname{lng}=e n \& n r m=i s o$. Acesso em: 18 maio 2020.

FREIRE, Ana Maria Araújo. Indignação. In: STRECK, Danilo Romeu; REDIN, Euclides; ZITKOSKI, Jaime José (Org.). Dicionário Paulo Freire. Belo Horizonte: Autêntica Editora, 2018. p. 261-262.

FREIRE, Paulo. Pedagogia do Oprimido. 9.ed. Rio de Janeiro: Paz e Terra, 1981.

FREIRE, Paulo. Pedagogia da Autonomia: saberes necessários à prática educativa. São Paulo: Paz e Terra, 1996.

FREIRE, Paulo. Pedagogia da Indignação: cartas pedagógicas e outros escritos. São Paulo: Editora UNESP, 2000.

FREIRE, Paulo. Pedagogia da Esperança: um reencontro com a Pedagogia do Oprimido. 11.ed. São Paulo: Paz e Terra, 2003.

HERBERT, Sérgio Pedro. Cidadania. In: STRECK, Danilo Romeu; REDIN, Euclides; ZITKOSKI, Jaime José (Org.). Dicionário Paulo Freire. Belo Horizonte: Autêntica Editora, 2018. p. 77-78.

MACHADO, Alexsandro dos Santos. Contar para viver: o (re)conhecimento da vontade de potência dos educadores pela narração de suas histórias de 
vida. Porto Alegre: Nova Prova, 2005.

MACHADO, Alexsandro dos Santos. Intuições para uma Pedagogia da Intuição: amizade enquanto uma Experiência Integral pela Dinâmica das Cartas. 2012. 179f. Tese (Doutorado em Educação) - Programa de Pós-Graduação em Educação, Universidade Federal do Rio Grande do Sul, Porto Alegre, 2012.

MACHADO, Alexsandro dos Santos; ARENHALDT, Rafael. O projeto Juventude em Ação e suas pedagogias: narrativas acon-tecidas e emergentes. In: CAYE, Márcio Marquetto (Org.). Projeto liderança - juventude em ação: protagonismo juvenil e perspectivas. Lajeado: Ed. da Univates, 2016. p. 117-135.

MATURANA, Humberto. Emoções e linguagem na educação e na política. Tradução: José Fernando Campos Fortes. - Belo Horizonte: Ed. UFMG, 1998.

PASSEGGI, Maria da Conceição. Memoriais: injunção institucional e sedução autobiográfica. In: PASSEGGI, Maria da Conceição; SOUZA, Elizeu Clementino (Org). Autobiografia: formação, territórios e saberes. Natal: EDUFRN; São Paulo: PAULUS, 2008. p. 103131.

PASSEGGI, Maria da Conceição. Narrar é humano! Autobiografar é um processo civilizatório. In: PASSEGGI, Maria da Conceição; SILVA, Vivian Batista da. (Org.). Invenções de vidas, compreensão de itinerários e alternativas de formação. São Paulo: Cultura Acadêmica, 2010. p. 103-130.

PASSEGGI, Maria da Conceição. Narrativa, experiencia y reflexión auto-biográfica: por una epistemología del sur en educación. In: ARANGO, Gabriel Jaime Murillo. (Org.). Narrativas de experiencia en educación y pedagogía de la memoria. Ciudad Autónoma de Buenos Aires: Editorial de la Facultad de Filosofia y Letras Universidad de Buenos Aires, 2015. p. 103-132.
PASSEGGI, Maria da Conceição; NASCIMENTO, Gilcilene; OLIVEIRA, Roberta de. As narrativas autobiográficas como fonte e método de pesquisa qualitativa em Educação. Revista Lusófona de Educação, 33, p. 111-125, 2016. Disponível em: https://revistas.ulusofona.pt/index.php/rleducacao/article/view/5682 Acesso em: 10 abr. 2020.

PASSEGGI, Maria da Conceição; OLIVEIRA, Roberta Ceres de; CUNHA, Luciana Medeiros da. Constituição de fontes para a pesquisa qualitativa em educação: grupo reflexivo de mediação biográfica e quadro de escuta. Investigação Qualitativa em Educação/ Investigación Cualitativa en Educación, Volume 1, Atas... CIAIQ, 2018.

PLOTINO. Tratado das Enéadas. São Paulo: Polar Editoral, 2000.

SANTOS, Boaventura de Sousa. Renovar a teoria crítica e reinventar a emancipação social. Tradução Mouzar Benedito. São Paulo: Boitempo, 2007.

SOUZA, Francisco Josivan de. 0 percurso do Outro: um currículo para a outreidade como educação libertadora a partir de Lévinas, Dussel e Freire. 2013. $179 \mathrm{f}$. Tese (Doutorado em Educação) - Programa de Educação: Currículo, Pontificia Universidade Católica de São Paulo, São Paulo, 2013.

STRECK, Danilo R. Pedagogia(s). In: STRECK, Danilo Romeu; REDIN, Euclides; ZITKOSKI, Jaime José (Org.). Dicionário Paulo Freire. Belo Horizonte: Autêntica Editora, 2018. p. 358-359.

WRIGHT-MILLS, Charles. A Imaginação Sociológica. Rio de Janeiro: Zahar Editores, 1972.

Recebido em: 30/05/2020 Revisado em: 04/08/2020 Aprovado em: 07/08/2020

Rafael Arenhaldt é doutor em Educação pela Universidade Federal do Rio Grande do Sul (UFRGS). Professor adjunto da Faculdade de Educação e Professor Permanente do Programa de Pós-Graduação em Ensino na Saúde da Faculdade de Medicina da UFRGS. Líder do Núcleo de Estudos Educação e Gestão do Cuidado da UFRGS, vinculado ao Conselho Nacional de Desenvolvimento Científico e Tecnológico (CNPq). E-mail: rafael.arenhaldt@ufrgs.br

Alexsandro dos Santos Machado é doutor em Educação pela Universidade Federal do Rio Grande do Sul (UFRGS). Professor adjunto da Universidade Federal Rural de Pernambuco (UFRPE). Pesquisador do Núcleo de Estudos Educação 
e Gestão do Cuidado da UFRGS, vinculado ao Conselho Nacional de Desenvolvimento Científico e Tecnológico (CNPq). E-mail: alexsandro.santosmachado@ufrpe.br

Irene Reis dos Santos é mestranda em Ciências da Educação pela Universidad de la Empresa (UDE) - Uruguai. Integra o Núcleo de Estudos Educação e Gestão do Cuidado da Universidade Federal do Rio Grande do Sul (UFRGS), vinculado ao Conselho Nacional de Desenvolvimento Científico e Tecnológico (CNPq). Fundadora e presidente da associação Comunidade Reinventando a Educação. E-mail: irenereisdossantos@gmail.com

Erika Cristina Lima da Silva Santiago é licenciada em Educação Física pela Universidade Federal de Pernambuco (UFPE) e especializanda em Neuropedagogia com enfase em Inclusão Escolar no Centro Universitário FACOL. E-mail: erikacristinalima.9@gmail.com 